\title{
Clark County monitoring system
}

\author{
I. L. Navis ${ }^{1} \&$ S. H. Conway ${ }^{2}$ \\ ${ }^{1}$ Clark County Department of Comprehensive Planning, \\ Nuclear Waste Division, USA \\ ${ }^{2}$ Urban Environmental Research, LLC, USA
}

\begin{abstract}
Since 1988, Clark County has been designated by the Department of Energy (DOE) as an "Affected Unit of Local Government" (AULG). The AULG designation is an acknowledgement by the federal government that activities associated with the Yucca Mountain proposal could result in considerable impacts on Clark County residents and the community as a whole.

In 2004, Clark County Comprehensive Planning Department's Nuclear Waste Division implemented a Monitoring Program designed to capture changes to the social, environmental, and economic well-being of its residents resulting from the Yucca Mountain Project and other significant events within the County. The Monitoring Program acts as an "early warning system" that allows Clark County decision makers to proactively respond to impacts from the Yucca Mountain Project. This paper provides an update on our Monitoring Program that has been refined and expanded to monitor changes not only for Clark County governmental agencies, but also regional agencies across Southern Nevada and all of the incorporated jurisdictions within Clark County. The paper will examine the lessons learned in implementing a Monitoring Program at this scale and is designed to track impacts that may result from High-Level Nuclear Waste (HLNW) and spent fuel shipments to Yucca Mountain.

Keywords: Yucca Mountain, Clark County, Nevada, monitoring, environmental indices, economic indices, nuclear waste transportation, environmental stigma, valuation.
\end{abstract}

\section{Background research}

\subsection{Environmental valuation}

The field of environmental economics joins two distinct branches of science in order to better understand the intersection phenomena in the natural and social 
world. Zhang and $\mathrm{Li}$ [14] stressed the importance of the difference between value and price. Valuation, the process of placing a value on environmental features is more complex than a simple dollar for dollar calculation of the cost; it must also take into account the social and environmental consequences of action (or inaction). Winkler [13] noted that before the sciences can be combined it is important to note the nature of value in both ecological and economic terms. Ecological valuation, according to Winkler, is inherent within the land, life, and resources in an area independent of the needs and desires of human kind. Thus the value of the environment exists primarily in the ecosystem's innate ability to sustain itself. Economic valuation, conversely, is nearly completely associated with the needs and wants of humans. Supply-and-demand and cost-benefit are phrases associated with economic valuation. Environmental economics seeks to balance the costs/benefits to the natural world with the costs/benefits to the human world.

According to King and Mazzotta [6] valuation is a primary factor in the risk/benefit equation in environmental economics. In a comprehensive valuation website King and Mazzotta detailed eight methods for calculating monetary figures for Environmental Valuation. These included: the Market Price Method; the Productivity Method; the Hedonic Pricing Method; the Travel Cost Methods; the Damage Cost Avoided, Replacement Cost, and Substitute Cost Methods; the Contingent Valuation Method; the Contingent Choice Method; and the Benefit Transfer Method. These can be employed individually dependent on the type of data available to the researcher and the resultant type of information desired. These methods are typically employed when some direct change to the environment is under consideration, such as the construction of a water treatment facility or harvesting trees for commercial use. The next step in valuation is a cost-benefit analysis of the potential change. The Damage Cost Avoided, Replacement Cost, and Substitute Cost Methods particularly lend themselves to the prediction of environmental and economic impacts as a result of unexpected incidents or events. Using hypothetical situations, these methods predict changes in value to an environment in the event of realistic events.

Fluctuations in the private home market represent a direct measure of environmental impacts on the local economy. Hazardous waste sites are considered by the public to be a nuisance at best and a severe health or environmental problem at worst. McLuskey and Rausser [8] studied changes in housing prices in proximity to hazardous waste facilities. Those authors indicated that the stigma of being located near a hazardous waste facility drives housing prices down. The event of a hazardous waste accident in proximity of homes has the effect of further depressing home prices and sales. The stigma, and therefore price drop, of affected areas can be either temporary or permanent, depending on the level of the incident and the length of time taken to remedy it. McLuskey and Rausser observed changes in single family home prices from 1979 to 1995 in proximity to West Dallas lead smelter that contaminated area soil. They found an additional negative impact in that appreciation of home values was lower among homes in closer proximity to the offending facility, than homes farther from it. Therefore neighbors of hazardous waste sites must take 
this into consideration when moving into the area or putting their homes on the resale market. Similar stigma is associated with living in proximity to a hazardous waste transportation route, and the market effects of an accident would be similar.

\subsection{Response to man-made environmental emergencies}

In recent decades several tragic events have occurred as a result of nuclear energy and other hazardous materials that can be used as models in measuring environmental devaluation. The nuclear reactor at the Chernobyl Nuclear power facility suffered a complete meltdown in April of 1986. The immediate death toll of the incident included more than 30 people and about 135,000 people were evacuated from homes and business within the immediate vicinity. The total cost of the Soviet economy as a result of the Chernobyl disaster has been about 12.8 billion dollars, without accounting for reduced production in the area from the migration of the workforce from contaminated to non-contaminated lands (chernobyl.co.uk). In the months following the tragedy travel to the area within $500 \mathrm{~km}$ (310 miles) of the site was discouraged, causing further devaluation of the area (Tveten et al. [11]). Jacob et al. [5] noted that many people in parts of Russia, Belarus, and the Ukraine continue to be exposed to harmful levels of radioactive materials as a result of the meltdown. Exposure to these materials has caused instances of thyroid cancer to skyrocket and has had a negative impact on life-sustaining potato crops and livestock. Even non-soviet republics such as Norway and the United Kingdom were affected by fallout from the nuclear explosion (Tveten et al. [11]). Thus the value of the environment in the years following the Chernobyl disaster cannot be measured solely in dollar figure terms, but also includes the ability to use and enjoy the land, as well as the health-related consequences of those who remain in proximity to the disaster site.

A similar nuclear disaster occurred in the United States in March of 1979 when reactor two (TMI-2) at Pennsylvania's Three Mile Island nuclear power facility had a similar meltdown. The incident, caused by human error, contaminated the surrounding area with a clean-up bill of about one billion dollars (Osif and Cunkling [10]). The United States Nuclear Regulatory Commissions' Fact Sheet on the Accident at Three Mile Island indicates that while there was some exposure of the population to radiation as a result of the TMI-2 reactor meltdown, children under the age of five and pregnant women were advised to evacuate the area surrounding the reactor as they were most susceptible to the harmful effects of radiation exposure. The incident, abated without loss of life, caused significant stigma to the environment surrounding the three-mile island area despite the fact that experts reported minimal damage to humans or natural resources.

Though a non-nuclear event, Clark County, Nevada was home to the Pacific Engineering and Production Company (PEPCON) rocket fuel company, which exploded on May 4, 1998 (Ibitayo et al. [4]). In addition to loss of life, the economic toll as a result of the explosion included damages to homes, buildings and schools. Because land and homes became damaged and contaminated, 
Carroll et al. [2] found that home prices within the two-mile radius of the explosion site dipped by about eighteen percent. Prices and rates of sale rebounded upon the news that the PEPCON plant would be relocated. This indicates that a major portion of the stigma associated with hazardous materials is the mere presence of its source, and not necessarily existing contamination from it.

\subsection{Environmental and economic monitoring}

The cost-benefit figures derived from environmental valuation can be used to monitor changes. Guttorp [3] indicated that the field of "environmetrics" is a relatively new synthesis of environmental and economic studies. Since 1989 the United States Environmental Protection agency (EPA) has coordinated the Environmental Monitoring and Assessment Program to measure the overall health of the United States' environment. This program is designed to gauge the effect of pollution across the country on invertebrate life, which in turn affects the well being of the ecosystem at large. Other monitoring efforts by the EPA to measure levels of particulate matter that cause air pollution. Monitoring these can allow researchers to measure seasonal variations in addition to change over time using standard hypothesis testing (Millard [9]).

Bricker and Ruggiero [1] called for more comprehensive environmental monitoring; suggesting that human beings have an obligation to the environment and creatures in the natural world to act as a steward for the ecosystem affected by their inhabitants. A monitoring program should include regular testing of surface water, groundwater, climate, atmospheric chemicals as well as the impacts of these on natural resources. Additionally, the status of resources, changes, and ecological processes should be monitored in order to measure the effectiveness of environmental policies and serve as an "early warning" system for emerging issues (327). Once an issue is identified, baseline data can help to determine the magnitude of the issue as well as reveal the impacts of the problem on the ecosystem as a whole.

Similarly economic factors can be monitored at all jurisdictional levels. Measures of economic well being vary from jurisdictional level. On the national level, economic health can be measured in terms of relative currency value (Liao [7]) Other common national economic indicators include the Gross National Product, Gross Domestic Product, trade balances and other markers of positioning within the global economy. The current research focuses primarily on the local level. Changes to housing prices, income, population, and other factors can be monitored and compared to other cities to measure the relative economic health of the community. When these indicators are regularly monitored, statistically significant changes can be used to alert decision makers and the populace about impending economic news.

\subsection{The Yucca Mountain project}

Yucca Mountain, Nevada, approximately 90 miles northwest of Clark County Nevada is the proposed construction site of the nation's first and only high-level 
nuclear waste repository. The DOE plans to store 77,000 metric tons of radioactive wastes deep within the mountain. This is a byproduct of the 107 functional nuclear power plants in the United States as well as from federal nuclear weapons facilities. Many shipping routes both by rail and by truck have been proposed to transport HLNW to the facility; most of them include routing the hazardous waste through or near the densely populated and frequently visited Las Vegas metropolitan area. The proposed repository has repeatedly met opposition from state and local government officials as well as from residents of the area and citizens groups. Much of the opposition comes from fear of potential accidents related to the shipment of HLNW and environmental stigma that may reduce their property taxes or otherwise negatively affect their quality of life.

\section{The Clark County monitoring program}

A major function of environmental economics is a cost-benefit analysis of potential environmental or economic endeavors; in the end creating a balance between economic and environmental concerns. The Clark County Monitoring Program is a five-part analysis that takes into consideration both the economy and environment in addition to social and political issues among the residents of Clark County Nevada, USA. Clark County is home to Las Vegas, Nevada, an internationally renowned tourist destination. It also neighbors Yucca Mountain, which is slated to hold the nation's largest underground storage facility for HLNW. The Monitoring Program has been devised by scholars and stakeholders to establish a baseline understanding of environmental, social, and economic conditions in Clark County; and track changes to the environment, economy, and social climate as a result of the HLNW shipments to the Yucca Mountain repository.

The purpose of the proposed monitoring system is to provide an "early warning" of changes within the social, economic, and/or environmental wellbeing of Clark County and its residents. While some of the indicators are specific to measuring the impacts from the Yucca Mountain proposal, others are more general and can be influenced by a variety of factors. Thus, the monitoring system provides an integrated system for observing changes within Clark County. Because many questions about the nature and extent of the HNLW shipment campaign to Yucca Mountain remain, the monitoring system should be viewed as a dynamic, integrated system that will continue to evolve as additional information from DOE becomes available.

The monitoring system is composed of the five components. These components build on the baseline of data gathered for the Clark County Impact Report that was sent to the Secretary of Energy and the President of the United States before the decision by the President and Congress to proceed to the site characterization phase with the Yucca Mountain Project. The monitoring system also builds on the recent update to the Impact Report and on the surveys of various stakeholder groups and the general public that have been conducted over the past four years. When viewed holistically, these studies provide a 
comprehensive framework for assessing the impacts within Clark County from the Yucca Mountain Project. Each component has been designed to leverage the limited resources available for monitoring impacts.

\subsection{Elements of the program}

The Monitoring Program is based on selecting and scrutinizing performance indicators that provide an early warning that changes are occurring that could affect Clark County residents and/or governmental agencies. These indices are modeled after the Southern Nevada Index of Leading Economic Indicators (SNILEI), which is produced by the University of Nevada, Las Vegas. In fact, some of the economic indicators suggested for the monitoring system are part of SNILEI. The key difference between the SNILEI and the proposed monitoring system is that the SNILEI focuses on the overall economic well-being of all of Southern Nevada. The seven indices within the Monitoring Program focus on indicators that provide insight into how well Clark County governmental agencies are performing and monitors impacts from factors including the Yucca Mountain Project that might adversely affect services provided by these agencies. The Monitoring Program is comprised of seven indices: economic, environmental, public health and safety, community well-being, housing affordability, fiscal, and cost of living. These indices are composed primarily of outcome measures maintained on an Internet site for easy access by Clark County decision makers.

\subsubsection{Bi-annual survey}

To supplement the monthly indicator indices and the quarterly reports, an annual survey will be included as part of the monitoring system. This survey has been designed to provide richer detail on the perception of various stakeholders on how well Clark County is succeeding in delivering services and to identify the nature and extent of any impacts resulting from the proposed Yucca Mountain Project.

The survey focuses on gauging impacts to Clark County's well-being. This survey will be a county-wide survey of community well-being. This type of survey has proven a successful tool for measuring how Clark County residents perceive their quality of life. A public opinion survey is a valuable tool for identifying changes in public perception that may occur as a result of the Yucca Mountain Project. For example, over the last 15 years, a preponderance of surveys of Clark County residents has found broad opposition to the Yucca Mountain Project. If HLNW shipments commence, the public's opposition to the Yucca Mountain Project may result in an increased dissatisfaction with the quality of life within Clark County. If this occurs, it could be an early warning of even more dire future economic consequences. Clark County residents have repeatedly indicated in a variety of polls and surveys that they believe the quality of life within their community is quite satisfactory and Clark County decision makers have worked to maintain and increase the quality of life for its residents and visitors. 
The survey also measures stigma for various constructions, by questioning respondents on if they feel the construction of certain types of amenities, such as amusement parks, schools, factories, and HLNW transportation routes will positively or negatively affect their property values. Respondents have resoundingly expressed concerned for environmentally unfriendly amenities such as polluting factories and HLNW transportation routes. The complete results of the survey are published in an integrated annual report and are regularly updated and publicly available on the Monitoring Program's Internet site (www.monitoringprogram.com)

\subsubsection{Focused interviews with Clark County agencies}

Over the last three years, the Clark County Department of Comprehensive Planning's Nuclear Waste Division has been compiling a baseline of governmental agency capacity to absorb impacts from the Yucca Mountain Project. This baseline and a first estimation of impacts were compiled into the Clark County Impact Report that was submitted to the President of the United States, the Secretary of Energy, and Congress in February 2002. The Clark County Impact Report indicated that the impacts from the Yucca Mountain Project to governmental agencies within Clark County will be substantial. For example, the fiscal impact on the public safety agencies just to prepare for HLNW shipments to commence has been estimated at \$275 million (Clark County Impact Report February 2002). Because of the magnitude of the proposed project and the long lead-time necessary to adequately prepare, focused interviews with key Clark County agencies will continue over the duration of the proposed HLNW shipment campaign.

\subsection{Monitored indices}

A total of seven indices are measured in the Clark County Monitoring program. These indices are particularly important to assessing impacts of changes to the human and natural environments of Clark County. Since they are regularly tracked, slight changes over time can be monitored and potentially traced back to a source creating an ability to imply causation.

\subsubsection{Economic index}

The economic index is illustrated in Table 1. Changes in commercial occupancy rates can be an early indicator of a downturn in the business climate. While many factors including the normal economic cycle can lead to a downturn in commercial occupancy, there is the potential that stigma-related impacts from the proposed HLNW shipments may contribute or exacerbate downturns of this type. Similarly, changes in commercial building permit valuation, number of residential building permits, taxable sales, visitor volume, convention attendance, passenger counts, gross gaming revenues, employment, and unemployment rates can result from a variety of factors, including potential stigma-associated impacts resulting from HLNW shipments. While monitoring these indicators will not directly provide a measure of impacts that may result from the Yucca Mountain Project, they will provide an early warning that change 
is occurring in the economic well-being of the community that warrants additional investigation. If stigma associated with Yucca Mountain HLNW shipments is found to be a causal factor, then they will help provide needed data to estimate the extent of impact.

Table 1: $\quad$ Sample economic index.

\begin{tabular}{|l|l|l|l|l|}
\hline \multicolumn{2}{|c|}{} & \multicolumn{3}{c|}{ Value } \\
\hline Indicator & Period & Current & Prior Period & Prior Year \\
\hline Commercial Vacancy Rate & Jan 06 & $4.3 \%$ & $4.3 \%$ & $6.8 \%$ \\
\hline Commercial Building Permit Value & Jan 06 & $\$ 211,346,082$ & $\$ 133,664,405$ & $\$ 54,311,624$ \\
\hline Residential Units Permitted & Jan 06 & 4,150 & 2,944 & 2,164 \\
\hline Taxable Sales & Jan 06 & $\$ 2,709,996,661$ & $\$ 3,408,600,422$ & $\$ 2,445,311,624$ \\
\hline Visitor Volume & Jan 06 & $3,175,528$ & $3,073,799$ & $3,048,045$ \\
\hline Convention Attendance & Jan 06 & 738,289 & 193,095 & 931,769 \\
\hline Airport - McCarran & Jan 06 & $3,465,017$ & $3,522,714$ & $3,271,627$ \\
\hline Gross Gaming Revenues & Jan 06 & $\$ 987,698,755$ & $\$ 762,594,619$ & $\$ 793,079,755$ \\
\hline Employment & Jan 06 & 891,900 & 901,700 & 832,400 \\
\hline Unemployment Rate & Jan 06 & $3.9 \%$ & $3.5 \%$ & $4.2 \%$ \\
\hline
\end{tabular}

\subsubsection{Environmental index}

The environmental indicators provide an early measure of changes to the community environmental well-being (Table 2). Clark County has shown its commitment to improving air quality and water quality through the many initiatives that it has undertaken and resources that it has provided to meet regulatory standards. The air quality indicators include "good days," i.e. meets federal regulatory requirements, for carbon monoxide, ozone, particulate matter less than 10 and less than 2.5 microns. The water indicator measured is the number of gallons of treated water per day, per capita.

While many factors including growth rates and weather conditions can and will influence air and water quality, increased pollutants associated with HLNW shipments or an accident-related radiation release also could contribute to hindering the progress that Clark County has made in these areas.

Table 2: $\quad$ Sample environmental index.

\begin{tabular}{|l|l|l|l|l|}
\hline & \multicolumn{3}{|c|}{ Value } \\
\hline Indicator & Period & Current & Prior Period & Prior Year \\
\hline Air Quality (CO Days > Good) & Jul 04 & 0 & 0 & 0 \\
\hline Air Quality (Ozone Days > Good) & Jul 04 & 21 & 19 & 24 \\
\hline Air Quality (PM 10 Days > Good) & Jul 04 & 14 & 12 & 22 \\
\hline Air Quality (PM 2.5 Days > Good) & Jul 04 & 14 & 8 & 3 \\
\hline Water Treated (Gal.) per Day / Capita & Jul 04 & 55.6 & 55.3 & 56.2 \\
\hline
\end{tabular}

\subsubsection{Public health and safety index}

The proposed public health and safety index is composed of key indicators that were identified by the Clark County Fire Department, Metro, Clark County 
Health District, and University Medical Center as significant indicators that will provide decision makers with critical information needed to assess impacts from the Yucca Mountain Project (Table 3).

Table 3: $\quad$ Sample public health and safety index.

\begin{tabular}{|l|l|l|l|l|l|}
\hline \multicolumn{2}{|c|}{} & \multicolumn{3}{c|}{ Value } \\
\hline Indicator & Period & Current & Prior Period & Prior Year \\
\hline Number of Fire Dept. Incidents & Oct 04 & 7,771 & 7,864 & 7,759 \\
\hline Estimated Damage from Fires & Oct 04 & 954,562 & $6,544,435$ & $1,055,621$ \\
\hline No. Metro Crimes per 1,000 Residents & Oct 04 & 6.83 & 6.61 & 6.92 \\
\hline Avg. Metro Response Times (minutes) & Oct 04 & 5.00 & 5.00 & 5.00 \\
\hline Traffic Accidents per 1,000 Residents & Oct 04 & 1.00 & 1.00 & 1.00 \\
\hline $\begin{array}{l}\text { Birth Defects and chronic disease per 1,000 } \\
\text { Residents }\end{array}$ & Oct 04 & 0.20 & 0.20 & 0.20 \\
\hline
\end{tabular}

The indicators tracked within the public health and safety index includes; the number of fire department incidents, estimated damages from fires, number of crimes per 1,000 population, average response times, traffic accidents per 1,000 population, and birth defect and chronic disease per 1,000 residents. While all of the public health and safety indicators within this index are outcome measures that can change because of multiple factors, they each provide vital data that will need to be monitored closely if DOE proceeds with the Yucca Mountain Project. As additional data is available from the DOE, other direct measures of potential impacts from the Yucca Mountain Project will be integrated into the Monitoring Program. For example, the Clark County Fire Department and the Las Vegas Metropolitan Police Department indicate that their current monitoring systems will be expanded to incorporate specific Yucca Mountain-related information as the commencement of the HLNW shipment campaign nears. These data, when coupled with the annual Impact Assessment Report provides vital data for assessing Yucca Mountain-related impacts within Clark County.

Table 4: $\quad$ Sample fiscal index.

\begin{tabular}{|l|l|l|l|l|}
\hline \multicolumn{2}{|c|}{} & \multicolumn{3}{|c|}{ Value } \\
\hline Indicator & Period & Current & Prior Period & Prior Year \\
\hline Median Existing Home Value & Jan 06 & $\$ 285,000$ & $\$ 285,000$ & $\$ 251,000$ \\
\hline Median New Home Value & Jan 06 & $\$ 343,198$ & $\$ 238,957$ & $\$ 307,500$ \\
\hline Commercial Construction Permit Value & Jan 06 & $\$ 211,346,082$ & $\$ 133,644,405$ & $\$ 54,311,624$ \\
\hline Number of Existing Home Sales & Jan 06 & 3,257 & 4,234 & 3,587 \\
\hline Number of New Home Sales & Jan 06 & 2,067 & 3,144 & 2,007 \\
\hline Electric Meter Counts & Jan 06 & 687,009 & 684,027 & 654,579 \\
\hline Taxable Retail Sales - All Activity & Jan 06 & $\$ 2,709,996,661$ & $\$ 3,408,600,422$ & $\$ 2,445,576,990$ \\
\hline Employment & Jan 06 & 891,900 & 901,700 & 832,400 \\
\hline
\end{tabular}




\subsubsection{Fiscal index}

The fiscal indicators monitor the financial well-being of Clark County governmental revenues (Table 5). Each of these indicators has a direct or indirect impact on Clark County's revenue stream.

\subsubsection{Quarterly indicator reports}

In addition to the monthly indicator indices, the Monitoring Program includes quarterly reports that will examine the trends within each of the indices in greater depth. These quarterly reports will allow additional factors to be evaluated, as appropriate. The quarterly reports, like the monthly indicators, focus on outcome measures that can be used by decision makers to identify changes within Clark County on a near-term basis. The quarterly reports will be maintained on the Internet site so that they can be easily accessed.

\subsection{Impacts of the monitoring program}

The indices, the quarterly reports, and the survey provide an early warning of impacts to Clark County residents and governmental agencies. The findings from each of these components of the Monitoring System will periodically be used to update the Clark County Impact Report. The updated Clark County Impact Report will integrate the findings from each of these components of the Monitoring System with a review of capacity issues and other impact issues that are being experienced by Clark County governmental entities as a result of the Yucca Mountain Project. Thus, the Clark County Impact Report will go beyond being an "early warning" system to provide a comprehensive assessment of the challenges being faced by Clark County residents and governmental agencies, as a result of DOE's efforts to site a HLNW repository at Yucca Mountain.

\section{Conclusions}

The Clark County Monitoring Program brings together both the environmental and economic indices to measure the health of Clark County, Nevada. This project was begun in 2004, well before shipments of Nuclear Waste were slated to be shipped through the area. The Monitoring Program has evolved and expanded over time, as municipalities and other stakeholders have realized the value of environmental and economic monitoring. In the event of a nuclear incident as a result of the shipment of HLNW through the area, the Monitoring Program will allow the measurement of over time changes in both the fiscal and ecological health of the area.

\section{References}

[1] Bricker, Open \& Michael Ruggiero. 1998, Toward a National Program for Monitoring and Environmental Resources. Ecological Applications 8:326329. 
[2] Carroll, T., T Clauretie, J. Jenson, and M. Waddoups. 1996. The Economic Impact of a Transient Hazard on Property Values: The 1998 PEPCON Explosion in Henderson, Nevada. Journal of Real Estate Finance and Economics, 13:143-167.

[3] Guttorp, Peter. 2000. Environmental Statistics. Journal of the American Statistical Association. 95:289-292.

[4] Ibitaya, Olurominiyi, Alvin Mushkatel, and K. David Pijawka. 2004. Social and Political Amplification of Technological Hazards, the Case of the PEPCON Explosion. Journal of Hazardous Materials A114:15-25.

[5] Jacob, P., S. Fensenko, S. K. Firskova, I. A. Likhtarev, C. Schotola, R. M. Alexakhin, Y.M. Zhuchenko, L. Kovgan, N. I. Sanzharova, and V. Ageyets. 2001. Remediation Strategies for Rural Territories Contaminated by the Chernobyl Accident. Journal of Environmental Radioactivity 56:51-76.

[6] King, Dennis and Marisa Mazzotta. 2001. Ecosystem Valuation. http://www.ecosystemvaluation.org. Accessed May 2006.

[7] Liao, Kun-jung. 2001 The Developmental State, Economic Bureaucracy and Financial Crisis in Asian Societies. Journal of Contingencies and Crisis Management. 9:36-45.

[8] McCluskey, Jill J. and Gordon C. Rausser. 2003. Hazardous Waste Sites and Housing Appreciation Rates. Journal of Environmental Economics and Management 45: 166-176.

[9] Millard. Steven P. 1987. Environmental Monitoring, Statistics, and the Law: Room for Improvement. The American Statistician 4:249-253.

[10] Osif, Bonnie Anne and Thomas W. Conkling. 1995. The Three Mile Island Unit 2 Decontamination and Recovery Collection. Journal of Government Information 5:413-420.

[11] Tveten, Ulf, Lisbeth I, Bryndilsen, Ignar Amundsen, and Tone D. S. Bergan. 1998. Economic Consequences of the Chernobyl Accident in Norway in the Decade 1986-1995. Journal of Environmental Radioactivity 41:233-255.

[12] United States Nuclear Regulatory Commission 2004. Fact Sheet on the Accident at Three Mile Island. http://www.nrc.gov. Accessed May 2006.

[13] Winkler, Ralph. 2005. Valuation of Ecosystem Goods and Services Part 1: An Integrated Dynamic Approach. Ecological Economics. http://www.elsevier.com. Accessed May 2006.

[14] Zhang, Yaoqi and Yiqing Li. 2005. Valuing or Pricing Natural and Environmental Resources. Environmental Science and Policy 5:179-186. 